\title{
A brief history of carotid-cavernous fistula
}

\author{
Min Lang, MS, ${ }^{1}$ Ghaith Habboub, MD, ${ }^{2}$ Jeffrey P. Mullin, MD, MBA, ${ }^{2}$ and Peter A. Rasmussen, $M D^{1,2}$ \\ ${ }^{1}$ Cerebrovascular Center and ${ }^{2}$ Department of Neurosurgery, Cleveland Clinic, Cleveland, Ohio
}

\begin{abstract}
Carotid-cavernous fistula was one of the first intracranial vascular lesions to be recognized. This paper focuses on the historical progression of our understanding of the condition and its symptomatology-from the initial hypothesis of ophthalmic artery aneurysm as the cause of pulsating exophthalmos to the recognition and acceptance of fistulas between the carotid arterial system and cavernous sinus as the true etiology. The authors also discuss the advancements in treatment from Benjamin Travers' early common carotid ligation and wooden compression methods to today's endovascular approaches.
\end{abstract}

https://thejns.org/doi/abs/10.3171/2016.5.JNS152372

KEY WORDS carotid-cavernous sinus; fistula; pulsating exophthalmos; carotid ligation; history

$\mathrm{C}$ AROTID-CAVERNOus fistula (CCF) was one of the earliest recognized intracranial vascular lesions in history due to obvious clinical features such as pulsating exophthalmos. ${ }^{22,27}$ However, it wasn't until years after the first report of this condition that the etiology of CCF was elucidated. CCFs are abnormal vascular shunts that allow blood to flow from the internal or external carotid artery directly to the cavernous sinus (Fig. 1). These fistulas commonly lead to engorgement of draining veins and orbital venous congestion, resulting in clinical manifestations, such as vision decline, pulsating proptosis, cranial nerve palsies, headaches, tinnitus, conjunctival chemosis, and cephalic bruit. Furthermore, it can also lead to cortical venous reflux and cerebral venous hypertension. ${ }^{17}$ During the journey to the development of better treatment for $\mathrm{CCF}$, the field of endovascular neurosurgery was born. Currently, MRI and catheter-based angiography are the methods of choice for diagnosis, and endovascular obliteration is the mainstay of treatment.

\section{Early Cases}

The condition of pulsating exophthalmos was first described in 1809 by Benjamin Travers (Fig. 2; born on April 3, 1783, in Cheapside, London). ${ }^{47}$ The patient presented with proptosis, chemosis, and an ocular bruit. When the ipsilateral carotid artery was compressed, the exophthalmos improved and the bruit disappeared. Travers suggested that the condition was confined to the eye and was most likely due to aneurysm of anastomosis of the orbit or intraorbital aneurysm. ${ }^{47}$ In 1812, Dalrymple (1772-1947) reported a second case of pulsating exophthalmos..$^{10}$ Travers' proposed etiology was further supported by Guthrie (1785-1856) when he performed the first autopsy on a patient with pulsating exophthalmos in 1923 and observed bilateral large nut-sized aneurysms of the ophthalmic artery. ${ }^{20,23,33}$ In 1839, Busk (1807-1886) reported findings similar to Guthrie's, and the English school assumed that aneurysm of the ophthalmic artery was the underlying mechanism. ${ }^{7,27}$ In France, however, an autopsy report from Baron in 1835, even prior to Busk's report, showed an abnormal connection between the internal carotid and the cavernous sinus in a patient with pulsating exophthalmos. ${ }^{3}$ Unfortunately, his brief report largely escaped the attention of others. The idea of abnormal communication between the cavernous sinus and the carotid artery became recognized as the true source for the constellation of symptoms when Gendrin, Nelaton, and Hirschfeld reported similar autopsy findings in 1841,1856 , and 1857 , respectively. ${ }^{3,27}$ Furthermore, the autopsy reports demonstrated that the fistula was located intracranially rather than intraorbitally. In 1870, Delens' work on cadavers (Fig. 3) showed that

ABBREVIATIONS CCF $=$ carotid-cavernous fistula.

SUBMITTED October 13, 2015. ACCEPTED May 24, 2016.

INCLUDE WHEN CITING Published online September 16, 2016; DOI: 10.3171/2016.5.JNS152372. 


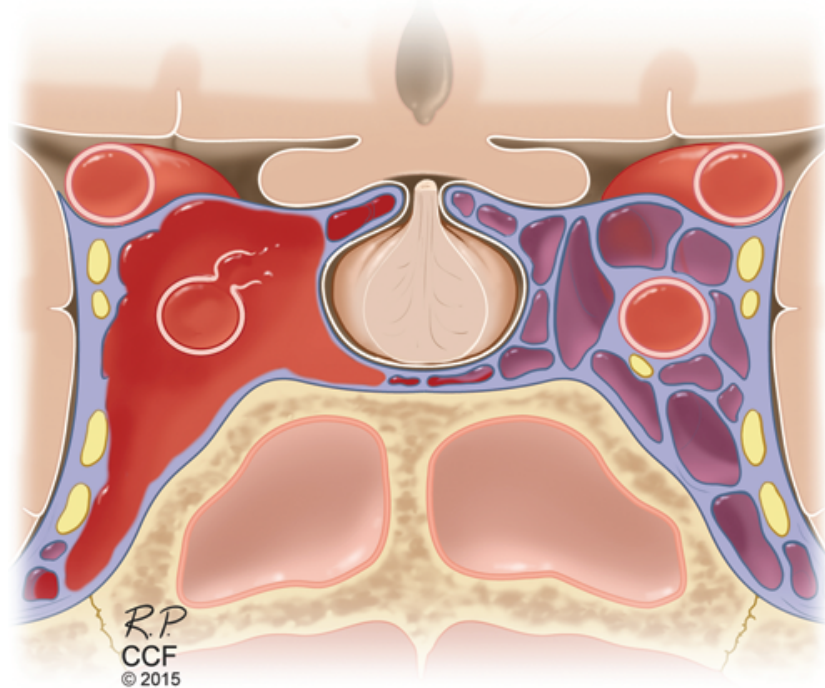

FIG. 1. Schematic representation of carotid-cavernous fistula in coronal section. Reprinted with permission, Cleveland Clinic Center for Medical Art \& Photography @ 2015-2016. All rights reserved. Figure is available in color online only.

the portion of internal carotid artery traversing the cavernous sinus was most likely to rupture under pressure, which was consistent with the notion of trauma-induced carotid-cavernous sinus fistulas. ${ }^{15}$ Rivington and Sattler independently published comprehensive work on the subject in 1875 and 1880, respectively, which helped the etiology of carotid-cavernous fistula gain broader acceptance. . $^{39,40}$ In 1935, Walter Edward Dandy (1886-1946) performed postmortem examinations on patients with pulsating exophthalmos and found that abnormal connection between the internal carotid artery and cavernous sinus could be due to an opening, severing of the artery, or weakening of the wall by arteriosclerosis. ${ }^{11,12}$

\section{Treatment}

Treatment for CCF has been refined over the years. The Hunterian ligation technique was popularized in the 1800 s to treat arterial aneurysms. In December 1785, John Hunter (1728-1793) treated a popliteal aneurysm in a young man by ligating the feeding femoral artery. ${ }^{9,45} \mathrm{Al}-$ though the artery ruptured 5 days after ligation, Hunter demonstrated that occlusion of the artery proximal to the aneurysm was a possible treatment option. Hunter would go on to improve the technique and in the words of his colleague, "...the plan conceived for the cure of popliteal aneurysms; which discovery will form an eternal monument of glory to its author." ${ }^{\prime 1,42}$

Although the technique was referred to as Hunterian ligation, Dominique Anel was arguably the true father of the technique. ${ }^{36,45}$ In 1808, Astley Cooper, Hunter's former student, attempted to treat a cervical aneurysm by ligating the common carotid artery, but the patient died of sepsis 3 weeks later. ${ }^{30}$

On May 23, 1809, Benjamin Travers, Cooper's pupil, ap-

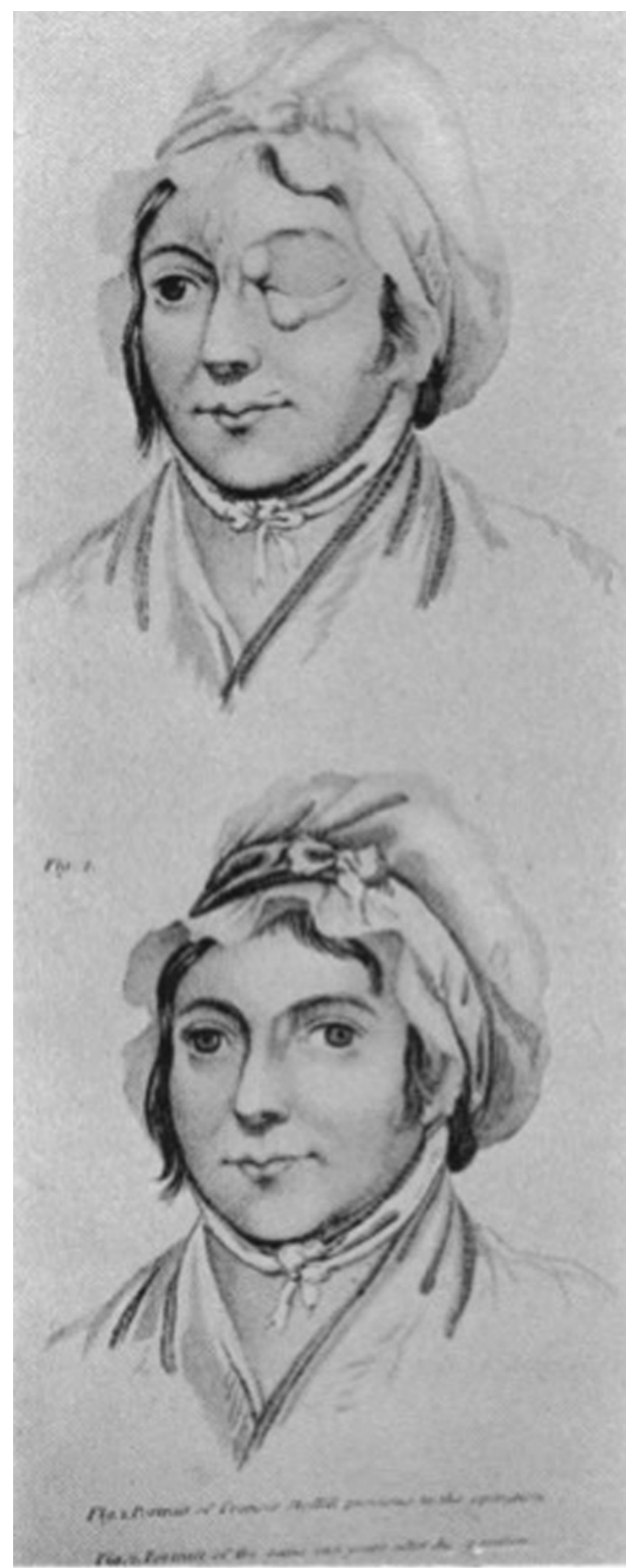

FIG. 2. Engraving depicting Locke's patient with pulsating exophthalmos before and after surgical treatment. From Travers B: Med Chir Trans 2:1-16, 420-421, 1811. Public domain. 


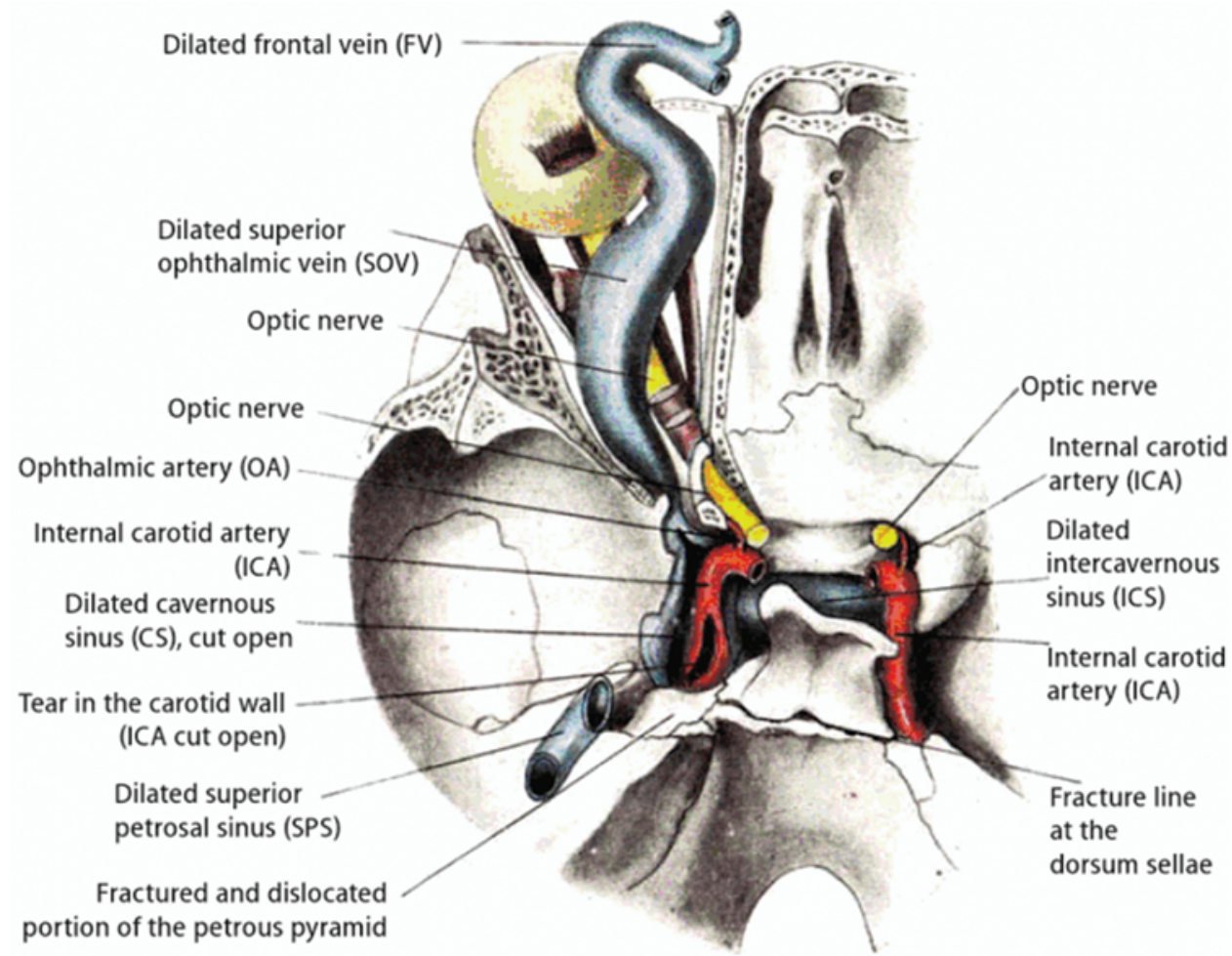

FIG. 3. Early drawing of Delens' 1870 case. The 17 -year-old patient presented with "pulsating exophthalmos" 6 months after a fall out of a carriage. She died 7 days after the operation due to pyemia. The carotid artery is penetrated and drainage into the intercavernous sinus, cavernous sinus, superior petrosal sinus, and superior ophthalmic vein can be seen. From Sattler $\mathrm{CH}$ : Pulsierender exophthalmus. In: Handbuch der Gesamten Augenheilkunde, Vol 9, @ Springer-Verlag Berlin Heidelberg, 1920, pp 114-115. With permission of Springer. Figure is available in color online only.

plied the techniques he had learned and performed ligation of the common carotid artery in a 28 -year-old female with unilateral pulsating exophthalmos; this became the first documented surgical treatment of $\mathrm{CCF}^{27,47}$ Over the next century, carotid artery ligation was the treatment of choice for CCF. However, high morbidity and mortality, dangers of hemiplegia, and fistula recurrence necessitated further refinement. ${ }^{14,16,17}$ In 1851, Brainard (1812-1866), professor of surgery at Rush Medical College, cured a case of pulsating exophthalmos by injecting a coagulating fluid into the dilated orbital veins; however, the patient developed vision loss in the affected eye., ${ }^{4,27}$ In 1856, Professor Gioppi was the first to recommend digital compression (Fig. 4).$^{18}$ Digital compression had been helpful in determining the extent of compression required to obliterate the fistula communication and candidacy for ligation, thus it was highly recommended prior to ligation operations. However, Raaf, Swan, and Locke warned against chronic daily compression protocols, which might actually increase circulation through the anastomosis and negatively impact subsequent ligation success. ${ }^{27,38}$ Noland reported a more conservative treatment approach-bed rest and compression of the eyeball, but this resulted in vision loss of the affected eye. ${ }^{6,32}$ Lansdown was the first to successfully perform orbital vein ligation for pulsating exophthalmos in $1874,{ }^{26}$ and this remained an alternative treatment method when other procedures failed. In 1904, Francis W. Murray from New York became the first person to attempt ligation of the internal carotid ar-

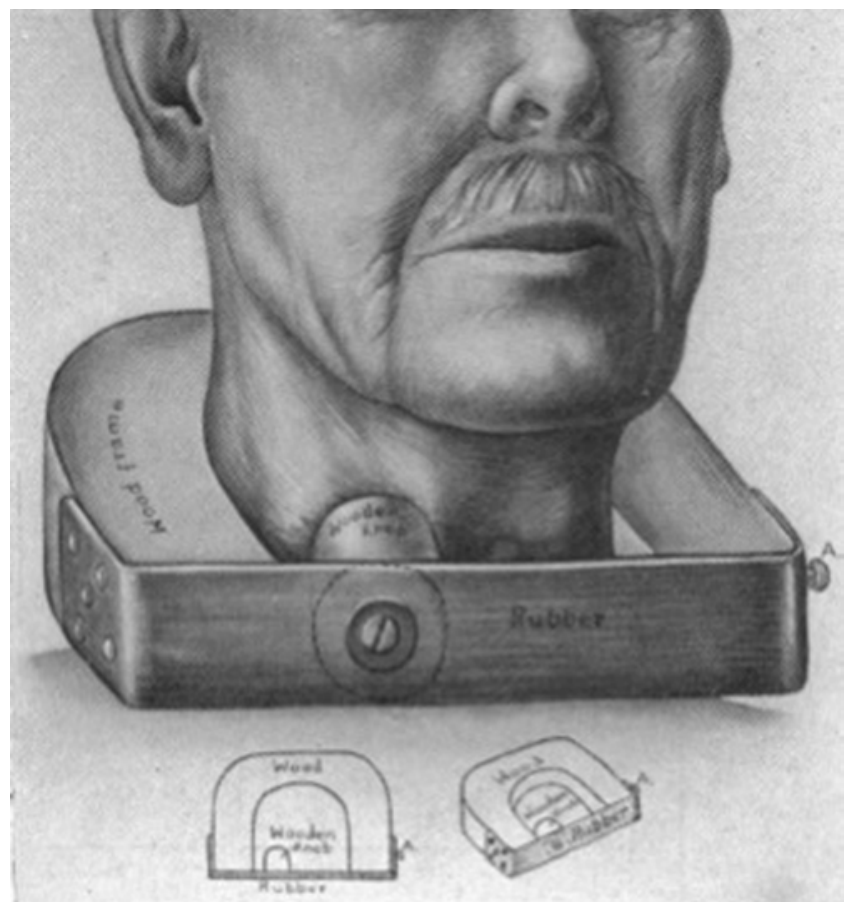

FIG. 4. An early external compression device used to compress the common carotid artery. From Locke CE: Ann Surg 80:272-285, 1924. Public domain. 
tery, as opposed to the traditional common carotid artery approach, for the treatment of CCF. ${ }^{31}$ However, Locke's comprehensive review of 588 cases showed that the results from internal carotid artery ligation were similar to the reported outcomes of common carotid artery ligation approaches. Moreover, Locke's careful autopsy work showed that direct fistula connection between the carotid artery and cavernous sinus was the main cause of traumatic CCF, whereas tumor, internal carotid artery aneurysm, and ophthalmic artery aneurysm etiologies accounted for a significant proportion of spontaneous CCF cases. ${ }^{27}$ In 1939, Walter Dandy published the first report of intracranial internal carotid artery clipping as a treatment for CCF (Fig. 5). ${ }^{13}$ The goal was to induce thrombosis within the lesion, leading to obliteration of the fistula. The procedure was carried out in patients who had been treated but not cured by extracranial carotid artery ligation and in whom the CCF was consequently trapped between the carotid ligature and the intracranial clip. ${ }^{13}$ In the article, Dandy states:

An ordinary flat silver clip was placed over the neck of the sac and tightly compressed, obliterating it completely. The clip was flush with the wall of the carotid artery. The sac, lateral to the silver clip, was then picked up with the forceps and thrombosed by the electrocautery. It shriveled to a thin shred of tissue. It is worthy of note that the aneurysm became much softer after the silver clip had been applied; it also ceased to pulsate.... ${ }^{13}$

In 1964, Hamby advocated for a more aggressive approach-intracranial suture ligation of the supraclinoid internal carotid artery. ${ }^{22}$ Subsequently, Hamby and Gardner incorporated "Barney Brooks' embolization technique," in which a flow-directed muscle embolus is introduced through the cervical internal carotid artery to occlude the CCF following carotid artery ligation. ${ }^{22}$ The "Brooks' method," however, is a misinterpretation by Hamby and Gardner, as Brooks never described the successful use of a muscle embolus to occlude a CCF with resulting cure of pulsating exophthalmos. As Brooks stated in his discussion to the Noland and Taylor paper, "Pulsating exophthalmos, the result of injury": "Owing to the curvature of the bony canal through which the carotid artery enters the intracranial cavity, it is difficult to be sure that our attempt to obliterate the artery at the site of the fistulous opening was successful." ${ }^{\prime}$

Hamby also believed that carotid-cavernous fistulas should be targeted directly like fistulas of the extremities rather than targeting the feeding arteries..$^{22}$ As Hamby stated: "As in other parts of the body the fistula itself should be attacked rather than attempting piecemeal progressive ligation of its feeding arteries." 22

Nevertheless, the lack of understanding of the cavernous sinus anatomical architecture in relation to the carotid artery made interventions difficult prior to the 1970s. The cavernous sinus was named by James Winslow in 1734 and was thought of as a large trabeculated venous cavern that completely surrounds the carotid artery, containing within it the third, fourth, and sixth cranial nerves as well as the V1 and V2 branches of the fifth cranial nerve. ${ }^{17,49}$ Venous corrosion specimen work by Parkinson from the 1960s and 1970s showed that cavernous sinus was neither a true sinus nor cavernous, but rather it was an irregular

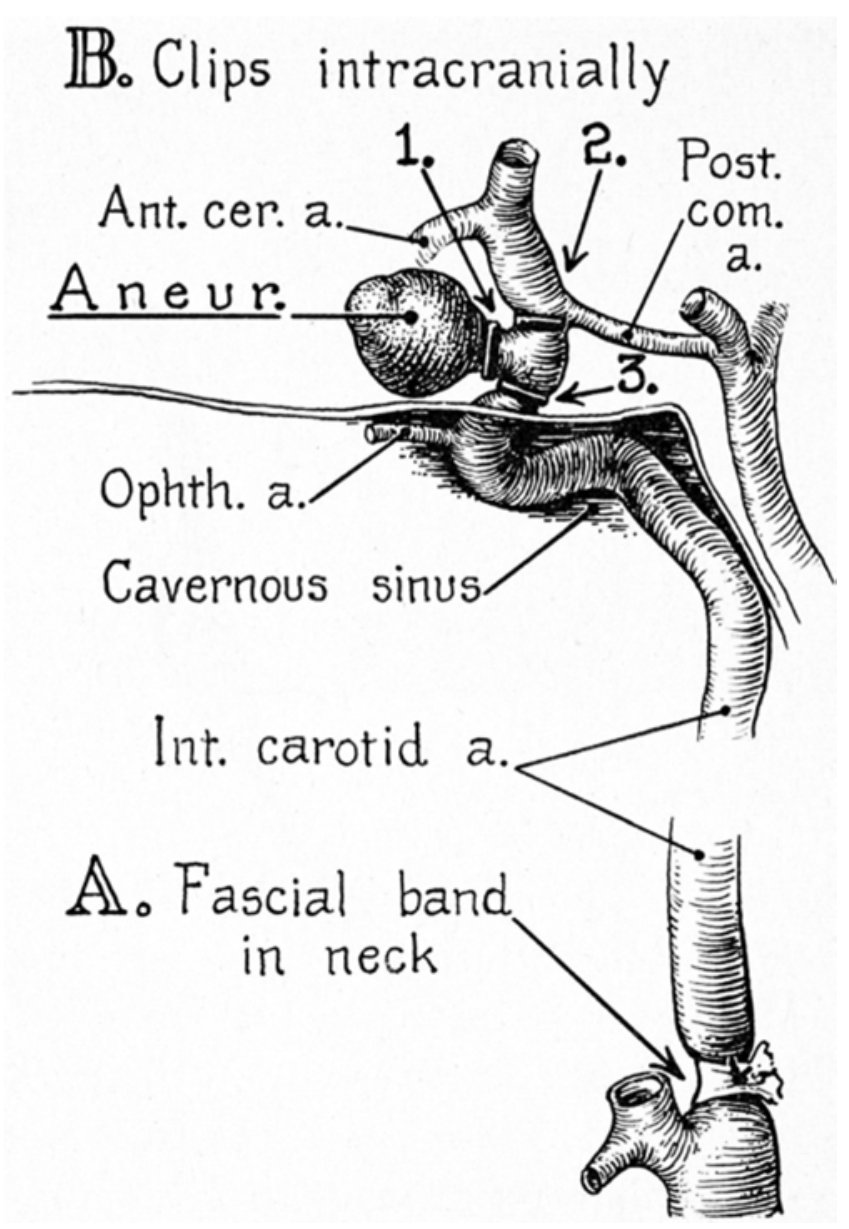

FIG. 5. Early illustration of intracranial clips used to treat internal carotid artery aneurysms. Aneur. = aneurysm; Ant. Cer. a. = anterior cerebral artery; Int. carotid a. = internal carotid artery; Ophth. a. = ophthalmic artery; Post. com. a. = posterior communicating artery. Reprinted from Walter E. Dandy: Intracranial Arterial Aneurysms. Copyright @ 1944 by Comstock Publishing Co., Inc.; renewed C 1972 by Mrs. Walter E. Dandy. Used by permission of the publisher, Cornell University Press.

venous plexus traveling around the carotid artery. ${ }^{34,35}$ This meant that surgeons could target the fistula directly without affecting the arterial and venous channels. In 1973, Parkinson reported 2 cases involving the successful use of a direct surgical approach that preserved the carotid artery, ${ }^{34}$ but the difficulty and precision of the procedure prevented it from being widely adopted. Parkinson stated in his paper: "The neurosurgeon is therefore required to make a rapid excursion through the tightly packed tangle of abnormally dilated, thickened, adherent veins to the underlying arterial wall as he dissects his way to the fistula." ${ }^{34}$

Fedor Serbinenko (born May 24, 1928, in Dmitriovsk in the former Soviet Union) completely changed the field of neurosurgery as he ushered in a new era of endovascular neurosurgery with the invention of the balloon catheter, which some people say was inspired by helium balloons that Serbinenko saw at the 1959 May Day celebration in Moscow's Red Square. ${ }^{46}$ The initial iterations of the bal- 

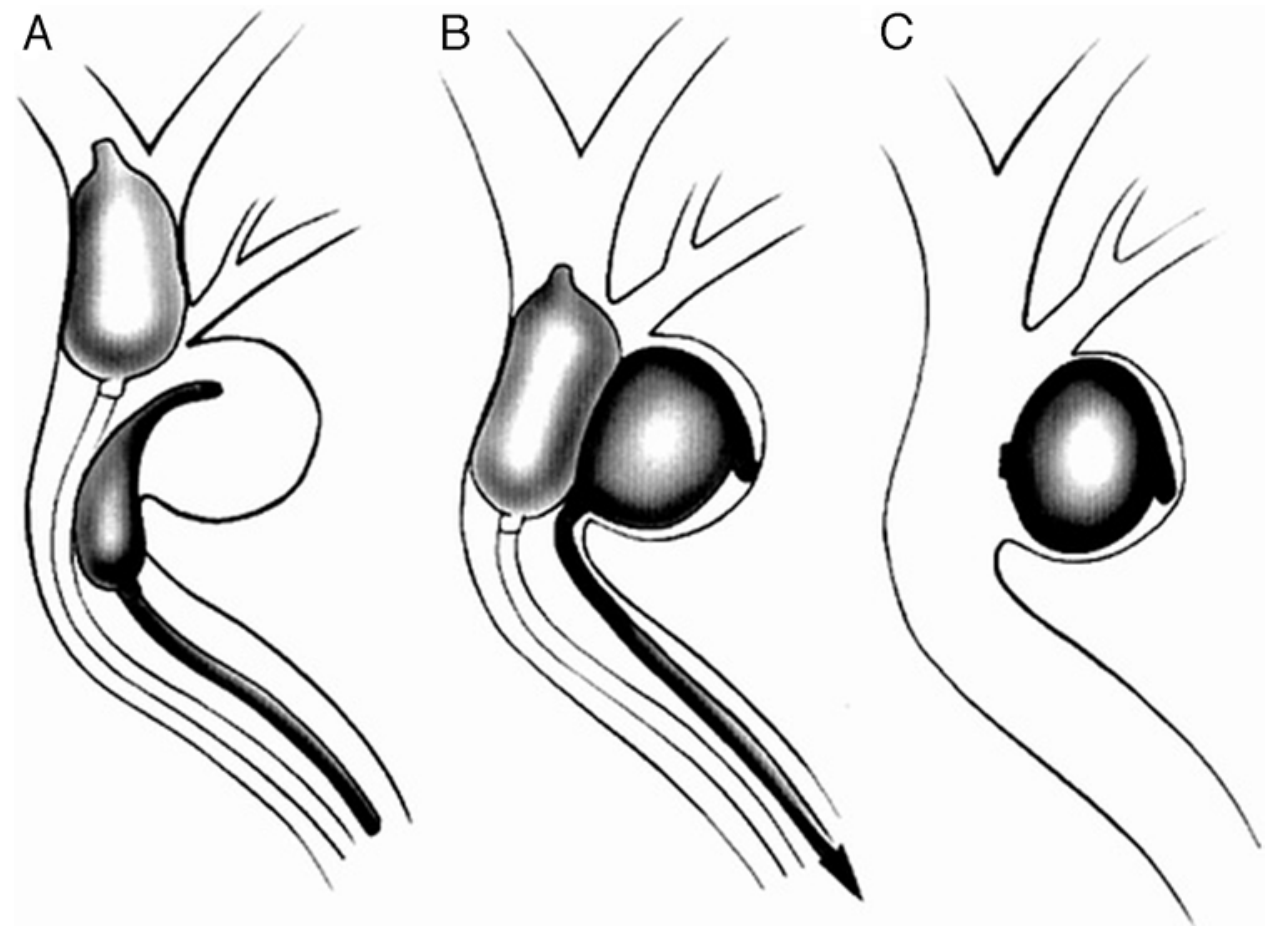

FIG. 6. Early illustration of the balloon embolization technique. A: The nondetachable balloon catheter guides the detachable balloon into the aneurysm sac. B: The detachable balloon is placed into the aneurysm sac with help from the nondetachable balloon. C: The detachable balloon is deployed to occlude the aneurysm. From Teitelbaum et al: A tribute to Dr. Fedor A. Serbinenko, founder of endovascular neurosurgery. Neurosurgery 46(2):462-470, 2000. Used with permission of Wolters Kluwer/Lippincott Williams \& Wilkins.

loon catheter were nondetachable and were primarily used by Serbinenko to aid in the diagnosis of major cerebral artery occlusions. ${ }^{46}$ In 1971, Prolo and Hanbery first attempted occlusion of a CCF using a nondetachable balloon, but the internal carotid artery was sacrificed as part of the procedure..$^{37}$ Serbinenko subsequently modified his balloon catheter design with a valve mechanism that allowed the balloon to be detached from the catheter (Fig. 6). In 1974, Serbinenko and colleagues were the first group to successfully treat CCF by occlusion using a detachable balloon catheter while preserving the internal carotid artery. ${ }^{43}$ Due to the Cold War, there was little exchange of scientific and medical knowledge between Russia and the Western world, and it took some time before Serbinenko's technique was adopted. ${ }^{50}$ Serbinenko was truly pivotal in the pioneering of endovascular neurosurgery.

As Serbinenko was working on perfecting the balloon catheter in the former Soviet Union, John F. (Sean) Mullan (1925-2015) was pioneering minimally invasive endovascular approaches at the University of Chicago. In 1974, he published his experiences of using thrombogenic techniques, such as direct current electrical thrombosis, stereotaxic copper electric needle thrombosis, and intracavernous thrombogenic wires, to treat CCF. According to his results, intracavernous wire thrombosis led to the better outcome as it preserved carotid flow. ${ }^{28}$ In a subsequent 1979 paper, Mullan recommended retrograde packing of the cavernous sinus, transjugular insertion of an occluding balloon, and thrombogenic wire and needles.$^{29}$ Mullan was one of the first to emphasize the importance of intraoperative angiography during endovascular neurosurgery.

Currently, transarterial and transvenous embolization with detachable metallic coils or liquid embolic agents ( $N$ butyl-2-cyanoacrylate or Onyx) is the primary treatment approach for CCF in the US. ${ }^{2,21,25,51}$ Drawbacks include cost and potential occlusion of important veins draining into the cavernous sinus. ${ }^{5}$ Similar to balloons, the coils may cause cranial nerve palsy. More recently, endovascular stent-grafts have been shown by Weber et al., ${ }^{48}$ Gomez et al., ${ }^{19}$ Archondakis et al., ${ }^{1}$ and Choi et al. ${ }^{8}$ to be an attractive alternative treatment for CCFs. The covered stent approach preserves parent artery blood flow and eliminates the risks of pseudoaneurysm formation and device rupture. ${ }^{24,44}$ Although a promising technique, the covered stents need to be made more flexible so they can be easily navigated through the tortuous intracranial vessels.

\section{Conclusions}

Treatment of CCF has come a long way since Travers' first surgical ligation procedure and external carotid compression by a crude wooden apparatus (Fig. 4). ${ }^{27}$ The high morbidity and mortality associated with historical CCF treatments has been dramatically reduced with modern endovascular approaches. ${ }^{17}$ With continuing advances in medical and endovascular technology, such as polytetrafluoroethylene-covered stents, the outcomes of CCF treatment will continue to improve. 


\section{References}

1. Archondakis E, Pero G, Valvassori L, Boccardi E, Scialfa $\mathrm{G}$ : Angiographic follow-up of traumatic carotid cavernous fistulas treated with endovascular stent graft placement. AJNR Am J Neuroradiol 28:342-347, 2007

2. Barber SM, Rangel-Castilla L, Zhang YJ, Klucznik R, Diaz $\mathrm{O}$ : Mid- and long-term outcomes of carotid-cavernous fistula endovascular management with Onyx and n-BCA: experience of a single tertiary center. J Neurointerv Surg 7:762-769, 2015

3. Baron: A case of ruptured internal carotid aneurysm in the cavernous sinus. Bull Soc Anat Paris 10:178, 1835

4. Brainard CW: Case of erectile tumor of the orbit, cured by iniltration with the solution of lactate of iron and puncture with hot needles after ligation of the carotid artery had failed. Lancet 62:162, 1853

5. Briganti F, Tortora F, Marseglia M, Napoli M, Cirillo L: Covered stent implantation for the treatment of direct carotid-cavernous fistula and its mid-term follow-up. Interv Neuroradiol 15:185-190, 2009

6. Brooks B: Discussion of Noland L and Taylor AS. Trans South Surg Assoc 43:176-177, 1931

7. Busk G: A case of aneurysmal tumor in the orbit. Med Chir Trans 22:124, 1839

8. Choi BJ, Lee TH, Kim CW, Choi CH: Endovascular graftstent placement for treatment of traumatic carotid cavernous fistulas. J Korean Neurosurg Soc 46:572-576, 2009

9. Cooper BB: Lectures on the Principles and Practice of Surgery, ed 2. Philadelphia: Blanchard \& Lee, 1852

10. Dalrymple W: A case of aneurism by anastomosis in the left orbit, cured by tying common trunk of left carotid artery. Med Chir Trans 6:111-123, 1815

11. Dandy WE: The surgical treatment of intracranial aneurysms of the internal carotid artery. Ann Surg 114:336-340, 1941

12. Dandy WE: The treatment of carotid cavernous arteriovenous aneurysms. Ann Surg 102:916-926, 1935

13. Dandy WE: The treatment of internal carotid aneurysms within the cavernous sinus and the cranial chamber: report of three cases. Ann Surg 109:689-711, 1939

14. De Schweinitz GE, Holloway TB: Sudden obstruction of the central artery of the retina, being a clinical record of five cases. Trans Am Ophthalmol Soc 11:471-501, 1908

15. Delens E: De la communication de la carotide interne et du sinus caverneux (anévrysme artérioveineux). Paris: Adrien Delahaye, 1870

16. Dorrance GM: Ligation of the great vessels of the neck. Ann Surg 99:721-742, 1934

17. Ellis JA, Goldstein H, Connolly ES Jr, Meyers PM: Carotidcavernous fistulas. Neurosurg Focus 32(5):E9, 2012

18. Gioppi G: Aneurisma dell' arteria oftalmica. Giornale d'oftalmol Italiana 165:445, 1858

19. Gomez F, Escobar W, Gomez AM, Gomez JF, Anaya CA: Treatment of carotid cavernous fistulas using covered stents: midterm results in seven patients. AJNR Am J Neuroradiol 28:1762-1768, 2007

20. Guthrie GJ: Aneurysms Within the Orbit: Lectures on the Operative Surgery of the Eye. London: S. Gosnell, 1823, pp $157-158$

21. Halbach VV, Higashida RT, Hieshima GB, Hardin CW, Pribram H: Transvenous embolization of dural fistulas involving the cavernous sinus. AJNR Am J Neuroradiol 10:377-383, 1989

22. Hamby WB: Carotid-cavernous fistula. Report of 32 surgically treated cases and suggestions for definitive operation. J Neurosurg 21:859-866, 1964

23. Jacas R, Ley A, Campillo D: Congenital intraorbital arteriovenous aneurysm. J Neurol Neurosurg Psychiatry 22:330-332, 1959
24. Kocer N, Kizilkilic O, Albayram S, Adaletli I, Kantarci F, Islak C: Treatment of iatrogenic internal carotid artery laceration and carotid cavernous fistula with endovascular stent-graft placement. AJNR Am J Neuroradiol 23:442446, 2002

25. Koebbe CJ, Horowitz M, Jungreis C, Levy E, Pless M: Alcohol embolization of carotid-cavernous indirect fistulae. Neurosurgery 52:1111-1116, 2003

26. Lansdown FP: A case of varicose aneurism of the left orbit, cured by ligature of the diseased vessels. BMJ 1:736, 1875

27. Locke CE: Intracranial arterio-venous aneurism or pulsating exophthalmos. Ann Surg 80:272-285, 1924

28. Mullan S: Experiences with surgical thrombosis of intracranial berry aneurysms and carotid cavernous fistulas. J Neurosurg 41:657-670, 1974

29. Mullan S: Treatment of carotid-cavernous fistulas by cavernous sinus occlusion. J Neurosurg 50:131-144, 1979

30. Mulliken JB, Burrows PE, Fishman SJ: Mulliken and Young's Vascular Anomalies, ed 2. Oxford: Oxford University Press, 2013, p 880

31. Murray FW: XI. The treatment of pulsating exophthalmos. Ann Surg 39:421-432, 432.1, 1904

32. Noland L, Taylor A: Pulsating exophthalmos, the result of injury. Trans South Med Soc 43:176-177, 1930

33. Nunneley T: Account of three cases of aneruism of or within the orbit, treated by ligature of the common carotid artery, with observations. Med Chir Trans 42:165-188, 1859

34. Parkinson D: Carotid cavernous fistula: direct repair with preservation of the carotid artery. Technical note. J Neurosurg 38:99-106, 1973

35. Parkinson D: Surgical anatomy of the lateral sellar compartment (cavernous sinus). Clin Neurosurg 36:219-239, 1990

36. Polevaya NV, Kalani MY, Steinberg GK, Tse VC: The transition from hunterian ligation to intracranial aneurysm clips: a historical perspective. Neurosurg Focus 20(6):E3, 2006

37. Prolo DJ, Hanbery JW: Intraluminal occlusion of a carotidcavernous sinus fistula with a balloon catheter. Technical note. J Neurosurg 35:237-242, 1971

38. Raaf J, Swan K: Traumatic carotid-cavernous sinus aneurysm. Am J Surg 80:816-828, 1950

39. Rivington W: A case of pulsating tumour of the left orbit, consequent upon a fracture of the base of the skull, cured by ligature of the left common carotid artery, subsequently to injection of perchloride of iron, after digital compression and other means of treatment had failed; with remarks, and an appendix containing a chronological résumé of recorded cases of intra-orbital aneurism. Med Chir Trans 58:183298,1875

40. Sattler CH: Pulsierender exophthalmus, in Graefe A, Saemisch T (eds): Handbuch der Gesamten Augenheilkunde. Vol 6. Pathologie und Therapie. Leipzig: Wilhelm Engelmann, 1880, pp 745-948

41. Scarpa A: A Treatise on the Anatomy, Pathology and Surgical Treatment of Aneurism. Wishart JH, trans. Edinburgh: Mundell, Doig, \& Stevenson, 1808

42. Schechter DC, Bergan JJ: Popliteal aneurysm: a celebration of the bicentennial of John Hunter's operation. Ann Vasc Surg 1:118-126, 1986

43. Serbinenko FA: Balloon catheterization and occlusion of major cerebral vessels. J Neurosurg 41:125-145, 1974

44. Singer RJ, Dake MD, Norbash A, Abe T, Marcellus ML, Marks MP: Covered stent placement for neurovascular disease. AJNR Am J Neuroradiol 18:507-509, 1997

45. Sloffer CA, Lanzino G: Historical vignette. Dominique Anel: father of the Hunterian ligation? J Neurosurg 104:626-629, 2006

46. Teitelbaum GP, Larsen DW, Zelman V, Lysachev AG, 
Likhterman LB: A tribute to Dr. Fedor A. Serbinenko, founder of endovascular neurosurgery. Neurosurgery 46:462-470, 2000

47. Travers B: A case of aneurism by anastomosis in the orbit, cured by the ligature of the common carotid artery. Med Chir Trans 2:1-16, 420-421, 1811

48. Weber W, Henkes H, Berg-Dammer E, Esser J, Kühne D: Cure of a direct carotid cavernous fistula by endovascular stent deployment. Cerebrovasc Dis 12:272-275, 2001

49. Winslow J: Exposition Anatomique de la Structure du Corps Humain. London: Prevast, 1734, Vol II

50. Wolpert SM: In re: Serbinenko FA. Balloon catheterization and occlusion of major cerebral vessels. J Neurosurg 1974;41:1974. AJNR Am J Neuroradiol 21:1359-1360, 2000

51. Yu Y, Huang Q, Xu Y, Hong B, Zhao W, Deng B, et al: Use of onyx for transarterial balloon-assisted embolization of traumatic carotid cavernous fistulas: a report of 23 cases.

AJNR Am J Neuroradiol 33:1305-1309, 2012

\section{Disclosures}

The authors report no conflict of interest concerning the materials or methods used in this study or the findings specified in this paper.

\section{Author Contributions}

Conception and design: Lang, Habboub, Mullin. Acquisition of data: Lang, Habboub, Mullin. Analysis and interpretation of data: Lang, Rasmussen. Drafting the article: Lang, Habboub, Mullin. Critically revising the article: all authors. Reviewed submitted version of manuscript: all authors. Approved the final version of the manuscript on behalf of all authors: Lang.

\section{Correspondence}

Min Lang, Cerebrovascular Center, Cleveland Clinic, 9500 Euclid Ave., Cleveland, OH 44195. email: langm@ccf.org. 